\title{
RECIL CR
}

National Cancer Institute

\section{Source}

National Cancer Institute. RECIL CR. NCI Thesaurus. Code C159618.

Complete disappearance of all target lesions and all nodes with long axis less than $10 \mathrm{~mm}$; greater than or equal to 30 percent decrease in the sum of longest diameters of target lesions (partial response) with normalization of FDG-PE. 